\title{
The interactive researcher as a virtual participant: A Habermasian interpretation
}

\author{
Fredrik Sandberg and Andreas Wallo
}

Linköping University Post Print

\section{Tweet}

N.B.: When citing this work, cite the original article.

Original Publication:

Fredrik Sandberg and Andreas Wallo, The interactive researcher as a virtual participant: A Habermasian interpretation, 2013, Action Research, (11), 2, 194-212.

http://dx.doi.org/10.1177/1476750313484503

Copyright: SAGE Publications (UK and US)

http://www.uk.sagepub.com/home.nav

Postprint available at: Linköping University Electronic Press

http://urn.kb.se/resolve?urn=urn:nbn:se:liu:diva-92388 


\title{
The interactive researcher as a virtual participant - A Habermasian interpretation
}

\begin{abstract}
This article explores the role of the interactive researcher by drawing on Jürgen Habermas' theory of communicative action to develop the concept of virtual participant. An ideal interactive research project is used to explore the issues faced by interactive researchers in three phases - initial, implementation and conclusion. In each phase, an interactive research project is used to demonstrate the issues that are discussed. First, this article argues that the concept of communicative rationality can be helpful to understand how mutually trusting relationships between practitioners and researchers can be established at the beginning of a project. Second, it argues that the idea of taking a virtual stand on validity claims can be used during a project to engage a performative attitude and achieve mutual understanding with actors in the practice system. Third, this article argues that the concept of the virtual participant can explain how the interactive researcher can engage in performative action without becoming captive to the practice system. The concept of the virtual participant helps to enhance understanding of the complexity of the role of the interactive researcher.
\end{abstract}

\section{Keywords}

Interactive research, virtual participant, action research, Habermas, communicative action, communicative rationality, performative action.

\section{Introduction}

Recently, interactive research has emerged as a new approach to collaborative research in the social sciences and organisational studies. Although this approach originates from the field of action research, interactive research can be viewed as an innovation in the sense that it refrains from attempting to solve practical problems in organisations and instead assists in creating opportunities for researchers and practitioners to engage in joint learning processes (Svensson, Ellström \& Brulin, 2007). Although some versions of action research have been criticised for downplaying the importance of building theory from experience (Dick, 2004; 2006), an important feature of interactive research 
involves developing theoretically related analysis aimed at both theoretical development and practical relevance (Ellström, 2008).

Some previous theoretical contributions have helped to frame interactive research as a methodology (Gunnarsson, 2007; Svensson \& Aagard Nielsen, 2006; Svensson, Ellström \& Brulin, 2007), and there are empirical studies in areas such as leadership (Wallo, 2008), empowerment (Larsson, 2006), gender equality (Amundsdotter, 2006), learning process in development networks (Holmquist, 2009), and ICT development (Vehviläinen, 2006), that illustrate this approach in practice. However, our knowledge of the relationship between the research system and the practice system must be further elaborated (Ellström, 2008). Such an in-depth theoretical discussion requires a robust framework that will enable a problematisation of the knowledge that is generated through interactive research and scrutiny of the conditions under which researchers should engage in organisational action and change. On this subject, Jürgen Habermas' theory of communicative action $(1984,1987)$ has offered important and interesting tools for understanding action research (cf. Aagaard Nielsen \& Steen Nielsen, 2006; Gustavsen, 1996; Kemmis, 2008; Wicks \& Reason, 2009; Johansson \& Lindhult, 2008). Furthermore, the role of action researchers has been previously discussed, for instance, from a historical perspective (Westlander, 2006), in terms of the ethical dilemmas that researchers encounter in the field (Morton, 1999; Trondsen \& Sandaunet, 2009; Walker \& Haslett, 2002), and with a focus on power relations and gender issues (Gunnarsson, 2006). In this paper, we draw on Habermas' work to enhance our understanding of the role of interactive researchers. Specifically, our aim is to develop the concept of virtual participant and to discuss the roles and actions of interactive researchers. However, it is important to clarify that this paper does not attempt to argue for a Habermasian perspective of interactive research. Rather, this study uses Habermas' theory to interpret the role of interactive researchers in this specific context. To engage in such a discussion, this paper uses a typical example of an ideal interactive research project that consists of initial, implementation and conclusion phases. Within this analysis, examples from the field are used to inform the discussion. The following question is the main concern in this article: how and to what extent should critical researchers engage in organisational action and change?

We hope that this paper provides insight on the role of interactive researchers and contributes to a more general discussion within the field of action research. Thus, we hope that this research contributes to previous debates in which Habermas' work has been addressed both implicitly and explicitly, such as debates on the topics of 
transformation (e.g., Lykes \& Mallona, 2008), the role(s) of action researchers (e.g., Trondsen \& Sandaunet, 2009; Johnsen \& Normann, 2004), communication (e.g., Maurer \& Githens, 2010) and power relations (Jacobs, 2010; Johansson \& Lindhult, 2008). In action research, the degree to which researchers have employed Habermas' theory has varied: for instance, Kemmis (2008) has been devoted to enhancing action research through a determined and thorough reading of Habermas, whereas Gustavsen (1993) has 'sampled' parts of Habermas and incorporated them into his framework for a democratic dialogue. Thus, it is difficult to clearly determine how Habermas contributes to the framework of Gustavsen's democratic dialogue. In this article, our goal is to remain closely aligned with Habermas' theory of communicative action in these discussions of the interactive researcher as a virtual participant. This alignment seems necessary to maintain the rigor that is needed to attest to the potential of using Habermas' work for enhancing interactive and action research as well as for organisational practice.

\section{Interactive research: an innovation within the field of action research?}

There is a long tradition of critiquing traditional positivistic research models in the social sciences for their objectification of participants and for producing knowledge of limited practical relevance (Ellström, 2008; Nowotny, Scott \& Gibbons, 2001). As an alternative, research models oriented towards participation and collaboration between researchers and practitioners have received increased attention (Gustavsen, 2008; Reason \& Bradbury, 2008). The action research approach, founded by Kurt Lewin in the 1940 s as a way of mobilising social science against authoritarian elements of society, is probably the best-known type of collaborative research (Svensson \& Aagaard Nielsen, 2006; Bradbury et al., 2008). For Lewin, the foundation of action research was the notion of the researcher's changing roles, from an external observer to a participant in concrete problem solving and real-life issues (Greenwood \& Levin, 1998).

Since Lewin's seminal work, action research has taken many different forms. In Great Britain, the Tavistock Institute for Human Relations used Lewin's ideas in their effort to rebuild the industrial base in the wake of World War II. The Tavistock Institute is linked to the development of the Industrial Democracy Project in Norway and Einar Thorsrud's sociotechnical model (Greenwood \& Levin, 1998). The Industrial Democracy Project gave workers new opportunities to control their own situation and helped to redefine the relationship between researchers and participants by giving the latter greater influence in the research process. However, sociotechnical theory has 
assumed different forms as researchers in different countries have adapted it. The democratic form that emerged in Norway contrasted with the North American model, where it became a tool for supporting high performance in industrial production (Greenwood \& Levin, 1998). Action research has since developed further. In Scandinavian action research, the democratic dialogue has been influential (Gustavsen, 1992; 1996) and is, to some extent, influenced by the theory of communicative action, with a focus on dialogue in research for development in working life.

What are the distinct features of action research? According to Svensson and Aagaard Nielsen (2006, p. 13):

... Action research is not seen as a collection of principles, with distinct theories and methods, but more as a perspective on how to conduct research. However, there must of course be an action component, that is, the research should support a normative change in one way or another [...] while at the same time producing new knowledge.

Similarly, Herr and Anderson (2005, p. 3) claim, "Action research is inquiry that is done by or with insiders to an organisation or community, but never to or on them". Other important features of action research include attempts to produce knowledge that is both highly practical and scientifically relevant and to maintain a normative orientation concerned with issues such as democratic processes, equality and emancipation. However, many action researchers consider normative goals, especially democracy or democratic processes, utopian (Svensson \& Aagaard Nielsen, 2006).

Recently, interactive research, a new form of collaborative research that focuses on joint learning processes between researchers and participants, has emerged in the Nordic countries (Johannisson et al., 2008; Svensson et al., 2002; Tydén, 2006). Interactive research can be viewed as a continuation and elaboration of the action research approach (Svensson, Ellström \& Brulin, 2007). Some action research approaches have been criticised for prioritising practical development at the expense of critical research. Interactive researchers consider this to be a significant problem, and they emphasise the importance of maintaining the division of labour between research and practice while continuing to build equal relationships between researchers and participants.

Interactive research can be depicted in a variety of ways, but we will limit our focus primarily to Svensson and Aagaard Nielsen's (2006) interpretation. They consider that the interactive relationship between the researcher and the practitioner facilitates a deeper understanding of organisations and access to issues that would otherwise remain 
hidden. Integrating insider and outsider perspectives in a joint analysis creates a foundation for the generation of new knowledge with greater validity than knowledge produced through one-sided approaches (Svensson \& Aagard Nielsen, 2006). This approach also creates the potential for greater commitment and participation on the part of the actors involved. Thus, an important condition for interactivity is that all actors must choose to participate and receive legitimate opportunities to influence the research process (Svensson, 2002).

The relationship between the researcher and the practitioner can be illustrated as two interacting activity systems: a research system and a practice system (Ellström, 2008):

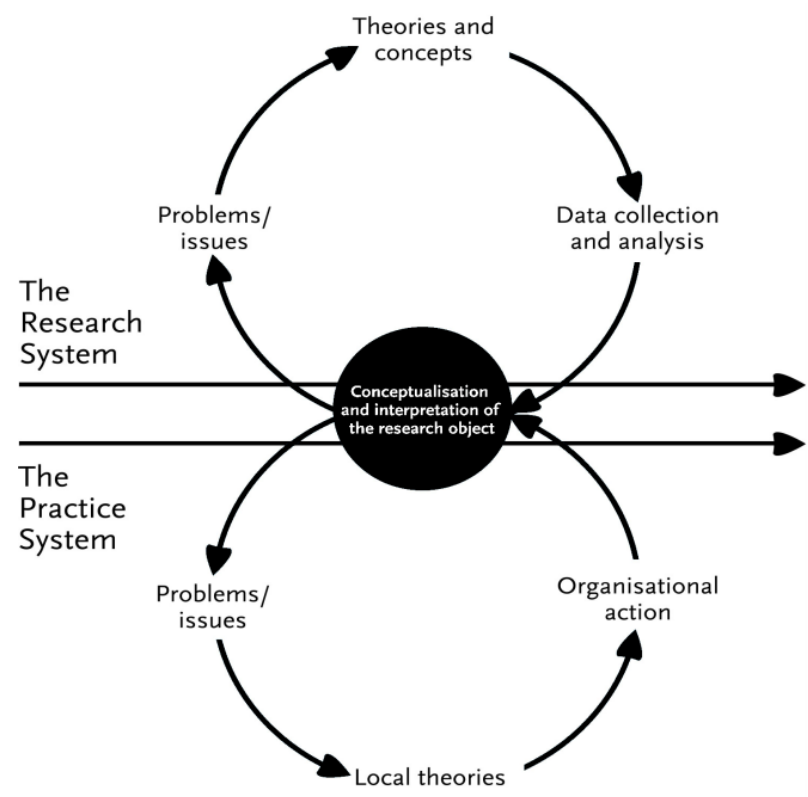

The research system can be described as a cycle driven by the researcher's problem formulations, theories, data collection and analysis. The practice system can correspondingly be seen as driven by the need to find knowledge and methods for solving problems in the organisation. The interactive model creates opportunities to establish a close link between these activity systems. A central tenet is that the process of interactive research is assumed to produce common conceptualisations and interpretations of the research object that are simultaneously fed back as input into the 
next cycle of problem-solving activities and into the next cycle of the research process. Because of this process of knowledge creation, the activity systems may be viewed as two joint, collective learning cycles that produce successive conceptualisations of the on-going change process (Ellström, 2008). The instrumental development work in the practice system does not concern the interactive researcher as much as the production of theoretical and scientific knowledge. Instead, the joint learning process is aimed at creating tools for practitioners to make sufficient changes themselves such that longterm development work can continue without the involvement of the researcher.

It is important to consider the consequences of this approach for the role(s) of the researcher. Svensson, Ellström and Brulin (2007) argue that interactive research can be seen as more complex than traditional research. The interactive researcher must partake in a development process without becoming captive to it and must alternate between onstage performance and back-stage reflection (Eikeland, 2006). However, interactive researchers must also consider the relevance of the critique, that action researchers are to some extent unable to maintain the distance from the practice necessary for conducting high quality and critical research (Svensson \& Aagard Nielsen, 2006). On this subject, Svensson, Ellström and Brulin (2007) argue that the ways in which the research process can be affected by the proximity of the two activity systems must be determined. Is it possible to establish a mutually trusting relationship with practitioners without the risk of 'going native', which jeopardises the role of the critical researcher? Are ethical considerations in the field underestimated at the expense of research and development interests?

\section{Communicative action, virtual participants and performativity}

To explore the interactive researcher's role, we draw on concepts and ideas from Habermas' theory of communicative action (1984, 1987). Habermas' theory posits how participants act based on mutual understanding and consensus. First, Habermas acknowledges that we can differentiate between the objective, social and subjective worlds. We raise truth claims in the objective world, normative claims in the social world and expressive and truthful claims in the subjective world. In communicative action, actors can bring their individual goals into a process of mutual understanding by addressing validity claims to raise or disapprove/approve a claim, thus harmonising their actions by mutually defining a situation with other actors (Habermas, 1984). 
However, the three worlds are also connected to different forms of rationality. Means-ends rationality is associated with the objective world, normative rationality is associated with the social world and expressive rationality is associated with the subjective world. When we are rational in all three forms, it is possible to talk about communicative rationality. In collaborative research, such as interactive research, these aspects are useful because communication is fundamental for these processes to work properly. There is a need for mutual understanding concerning the means and end of the process and the prescribed norms of action (how to act). Furthermore, actors must be able to express their thoughts and feelings.

The process of mutual understanding, which is the basis of communication between actors, also raises concerns regarding the role of Habermasian-inspired interactive researchers. Habermas (1984) argues that a researcher must interact and communicate with those involved in his/her study. Therefore, a researcher cannot stand completely outside of the communicative processes as an objective observer. However, the researcher should not involve himself or herself in the goal-oriented actions of the practice system. In other words, s/he must become a 'virtual participant': a researcher who participates virtually in communicative structures while maintaining the necessary critical distance from practice. As Habermas (1984, p. 114-120) states:

The social-scientific interpreter [...] participates in processes of reaching understanding and not for the sake of an end that requires coordinating the goaloriented actions of those immediately involved. The action system in which the social scientist move as an actor lies on a different plane [...] the social scientist does not pursue any aims of his own within the observed context [i.e., act goal-oriented] [...] the social scientist has to participate virtually in the interactions whose meaning he wants to understand, and if, further, this participation means that he has implicitly to take a position on the validity claims that those immediately involved in communicative action connect with their utterances, then the social scientist will be able to link up his own concepts with the conceptual framework found in the context of action [...]

The primary purpose of the researcher is to understand the communicative processes and, as will be argued below, to 'support', 'stir up' and 'steer' (cf. Svensson \& Nilsson, 2008) the learning processes. To accomplish the role as a virtual participant, the researcher must take on a performative attitude not an objectified attitude (Habermas 
1995). This means that the researcher must involve her/himself in the collaborative language processes to understand them. S/he must perform (communicate) with the participants involved but not involve him/herself in the goal-oriented actions of the practice system. A virtual participant is neither completely neutral and objective nor completely biased and subjective. Rather, there is a subtle balance between these positions, and the virtual nature of the actor is important to maintain this balance. Thus, Habermas' theory of communicative action offers theoretical input to examine the following aspects in interactive research: 1 . the role of the interactive researcher as a virtual participant; 2 . the theoretical understanding of how to create mutually trusting relationships between the research and practice systems (communicative rationality); 3 . how the idea of a virtual position on validity claims can be used to explain the interactive researcher's intervention in the language processes (to support, stir up or steer towards mutual understanding) without directly influencing the goal-oriented actions of the practice system.

There is an on-going discussion regarding the concept of performativity and the role of a researcher in relation to the object of research. Fournier and Grey (2000) consider a non-performative intent to be a pillar stone for the critical researcher by which s/he can resist attempts to "develop and celebrate knowledge which contributes to the production of maximum output for minimum input; it involves inscribing knowledge within means-ends calculation” (p. 17). However, as argued by Spicer, Alvesson and Kärreman (2009), non- or anti-performativity may prevent critical research from attempting to become socially influential and from promoting social change. Thus, there is a risk that the researcher will become captive to the so-called 'ivory tower'. As an alternative, Spicer et al. (2009) introduce the concept of critical performativity, which "involves active and subversive intervention into managerial discourses and practices. This is achieved through affirmation, care, pragmatism, engagement with potentialities, and a normative orientation” (p. 538). However, this kind of 'eclectic' theorising on performativity raises concerns because the boundaries of performativity become blurred. The concept of the virtual participant more clearly marks the boundaries of performativity, and Habermas' ideas about the performative attitude seem useful for discussions of interactive research, in which these boundaries must be clearly marked to prevent the interactive researcher from becoming captive to the practice system.

As discussed above, the joint learning process in interactive research aims to create tools for practitioners to make sufficient changes themselves such that long-term 
development work can continue without the involvement of the researcher. We argue that Habermas' theory of communicative action and the concept of the virtual participant can inform the interactive researcher, enabling him or her to participate in a development process without becoming its captive. The following section will explore these issues further.

\section{Analysing the role of an interactive researcher as a virtual participant}

To clarify how the role the interactive researcher resembles that of a virtual participant, this section discusses the three phases of an ideal typical interactive research project: the initial, implementation and conclusion phases. Additionally, each phase contains empirical examples from a case study of leadership in a small manufacturing company.

\section{Initial phase}

As mentioned previously, the process of knowledge creation in interactive research may be viewed as two collective learning cycles that produce successive versions of common conceptualisations of the on-going change process. Thus, in the early stage of an interactive research process, there is a strong need to build a communicative space (Newton \& Goodman, 2009; Wicks \& Reason, 2009) as a foundation for these joint learning cycles. In this communicative space, it is important to establish a legitimate relationship between the researcher and practitioner and to reach agreement concerning common goals and research questions that satisfy both the research and practice systems. Here, Habermas' idea of communicative rationality may be helpful. First, a typical interactive project starts with the process of identifying, conceptualising and interpreting the research object. What are the common interests between the research and practice systems? This process can typically be characterised as 'testing the water', and its length is usually related to the researcher and practitioners' familiarity with each other and with the interactive research model. We argue that it is important to be patient, to be mindful of power relationships and to encourage brainstorming activities and innovative thinking to prevent one actor (typically the researcher) from dictating the research agenda. However, power relationships between researchers and practitioners are not the only problematic relationships; it is also important to be mindful of the power relationships between practitioners. Second, there is a need to establish mutual understanding of the means-end of the process. What are the goals of the process, and 
how are these goals to be reached? What are the different roles for the practice system and the research system? Third, there is a need to reach consensus concerning the norms of action in the process. How should we act toward each other in the joint learning processes, and how can we be rational, in a normative sense, throughout a research project? In the table below we try to summarise the planning of an interactive research project based on communicative rationality.

After reaching a consensus and forming what can be understood as a mutual psychological contract, it is also important to establish a written contract that contains agreed-upon rules and norms for action during the research process (cf. Lundin \& Wirdenius, 1990). Furthermore, it is necessary to create conditions in which individuals are allowed to be expressive and to subjectively articulate their thoughts and feelings about 'testing the water', the construction of collective norms, mutual goals and the planning of the project (See table 1 below).

Table 1

\begin{tabular}{|l|l|l|l|}
\hline Theory & Practice system & Research system & Mutual system/channel \\
\hline $\begin{array}{l}\text { Means-end } \\
\text { rationality }\end{array}$ & $\begin{array}{l}\text { Identify specific goals } \\
\text { that support the } \\
\text { organisation's } \\
\text { development. }\end{array}$ & $\begin{array}{l}\text { Identify specific goals } \\
\text { that support the } \\
\text { development of theories } \\
\text { and research. }\end{array}$ & $\begin{array}{l}\text { Establish consensus } \\
\text { concerning mutual goals } \\
\text { and questions. }\end{array}$ \\
\hline $\begin{array}{l}\text { Normative } \\
\text { rationality }\end{array}$ & $\begin{array}{l}\text { Reach consensus } \\
\text { concerning specific } \\
\text { norms for action in the } \\
\text { practice system. }\end{array}$ & $\begin{array}{l}\text { In addition to following } \\
\text { the agreed-upon norms in } \\
\text { the research process, the } \\
\text { researcher is obligated to } \\
\text { follow prescribed norms } \\
\text { of research ethics. }\end{array}$ & $\begin{array}{l}\text { Establish prescribed } \\
\text { norms for legitimate } \\
\text { actions between practice } \\
\text { and research systems. }\end{array}$ \\
\hline $\begin{array}{l}\text { Expressive } \\
\text { rationality }\end{array}$ & $\begin{array}{l}\text { Allow members of the } \\
\text { organisation to express } \\
\text { their thoughts and } \\
\text { feelings. }\end{array}$ & $\begin{array}{l}\text { The researcher may } \\
\text { express thoughts and } \\
\text { feelings but is obligated } \\
\text { to follow the rules of } \\
\text { virtual participation. }\end{array}$ & $\begin{array}{l}\text { Ensure that all } \\
\text { subjective voices are } \\
\text { given the chance to be } \\
\text { heard. }\end{array}$ \\
\hline
\end{tabular}

Three things need to be addressed to ensure the success of this interactive process: time, openness and guidance. Time and openness are especially necessary in the beginning of a project because it is important that all actors involved reach a mutual understanding. The actors must understand each other even if they do not agree with each other. If the 
actors do not understand one another, this may cause subsequent conflicts. Thus, a strong and solid foundation is crucial. It may be appropriate for the researcher to record or take notes and, at the end of this process, to present what was discussed and agreed upon. Thus, the interactive researcher, as a virtual participant, plays the important role of supporting and steering the process while balancing this role with his/her own participation in the process of reaching mutual understanding as an actor in the research system. As previously argued, the researcher must balance the need to create a mutually trusting relationship with the practitioners and the risk of 'going native'.

The successful beginning of an interactive research project creates the potential for greater commitment and participation on the part of all actors involved. An important condition for interactivity is that all of the actors have chosen to participate and are given opportunities to influence the research process (Svensson, 2002). Ideally, this part of the project generates common goals for the project and a normative base for action, and these aspects are deliberated through mutual understanding in which all parties involved can express their thoughts and feelings subjectively. In Habermasian terms, the processes have worked by means of a communicative rationality.

For examples of the activities that occur during the initial phase of an ideal typical research project, we can examine the previously mentioned case study. Here, the initial phase comprised several meetings between the company representatives and the researchers to discuss their common research and development interests. In addition to these more common interests, the specific aims of both the practice and research systems were also defined. In these meetings, potential opportunities for collaboration were discussed, including the ways in which research could contribute to practice and, conversely, the ways in which practice could contribute to research. At that time, the company was expanding and had recently hired many new managers. Thus, the company representatives identified the need to examine the leadership skills of their managers in terms of their ability to lead change with a focus on increased sales and profitability. The researchers supported this interest but also problematised the economically oriented notion of change management by broadening the concept to include issues concerning learning and development. These meetings created a common understanding of the changing nature of leadership and generated ideas with regard to how such leadership could be examined and developed. The researchers drafted meeting minutes that were discussed and revised during subsequent meetings. Thus, the minutes constituted a type of contract for the research project. 


\section{Implementation phase}

In the practice system, the majority of the responsibility lies with organisational actors. The lines between research and practice are, at least theoretically, relatively easy to draw, but who is responsible for the overall progress of an interactive research project? For this responsibility to be shared between all involved actors, it is necessary to stress that common actions in the projects are based on communication and mutual understanding as the execution of the project is initiated.

When the project moves into the 'implementation' phase, the role of the virtual participant also changes. If the beginning of the project was primarily situated in the mutual channel, the implementation phase will push the virtual participant to move more frequently between being a researcher and a facilitator of the joint learning processes. Participating in a development process and collecting data on this process must be balanced, as noted previously, to prevent the researcher from becoming captive to the practice system. Thus, in this phase, there is a need to alternate between on-stage performance and backstage reflection (Eikeland, 2006). As a virtual participant, the interactive researcher participates in the language processes. In contrast to the supporting and steering role played in the initial phase, the focus should be on supporting and stirring up the discussions through critical engagement as long as the researcher does not violate the principle of directly influencing the goal-oriented actions of the practice system. At the same time, the virtual participant observes the processes and collects data for the research system. As mentioned previously, the (interactive) researcher "has to participate virtually in the interactions whose meaning he wants to understand, and if, further, this participation means that he has implicitly to take a position on the validity claims that those immediately involved in communicative action connect with their utterances" (Habermas, 1984, p. 120). Thus, during observations, interviews, focus groups and joint seminars, the researcher must take a virtual stand on truth claims, normative rightness and truthfulness without directly influencing the goaloriented actions in the practice system. This process requires further attention and explanation. First, it is important to emphasise that the researcher's responsibility is primarily to understand the processes and collect data. Second, the researcher is there to support and 'stir things up'. These roles can be explained through Habermas' idea of validity claims. First, imagine that an actor in the practice system raises a claim to normative rightness that violates either a norm within the project (for example, screams at a colleague) or another more general norm (for example, makes a racist joke). Here, the virtual participant can support the actors in the language processes by calling 
attention to the violation of the common contract signed in the initial phase (that people should act respectfully towards each other) or a more general societal norm (the importance of equality). Second, the virtual participant could 'stir things up' by questioning truth claims. Imagine a situation, such as a joint seminar, when a discussion amongst practitioners does not result in a discussion at all; instead, everyone almost immediately accepts a truth claim. It is possible to question the claim by, for instance, expressing personal thoughts and feelings concerning the issue at hand and posing questions that oppose the truth claim while not intervening directly.

However, sometimes the purpose of intervening in the language processes is simply to understand something (as a researcher) that cannot be grasped by listening as an outside observer. Here, the validity claims could be addressed as questions: You said that. . .? Is that correct. . .? You really felt like that. . . ? Why did you react so strongly? The researcher takes on a performative attitude, in contrast to being only an objective observer. The limitations and risks of this performativity can at least partially be explained by the concept of the virtual participant.

The close relationship enabled through interactive research can provide access to issues that would otherwise remain hidden. By integrating insider and outsider perspectives in a joint analysis, a foundation is created for generating new knowledge. However, this process may lead to the discovery of emerging and pressing issues that were not included in early conceptualisations of the research object. While this is one of the benefits of an interactive approach (sensitivity to the data and the ongoing processes in both the research and practice systems and changing the course of the project to pursue new and interesting themes), it may complicate the research process if such eventualities were not discussed in the initial phase. What happens to the mutually agreed-upon contract? Must it be re-negotiated, and how will changing the direction of a project affect structural factors such as funding and time frames? One possibility is to address emerging issues through follow-up seminars that revisit the agreed-upon goals and norms of the project. How do these emerging issues influence the original plan, the contract, or the researcher's theoretical framework (Vehviläinen, 2006)?

The general idea of the interactive model presented previously (Ellström, 2008) suggests that there is a division of labour between researchers and practitioners, and both are responsible for the actions in their respective systems. In other words, the researcher should primarily be responsible for traditional research activities, such as data collection. However, there are examples of interactive research projects in which the practitioners have become very involved and have even jointly published with the 
researcher (Larsson, 2006). This can be seen as problematic. The data collection methods and analysis should follow the conventions of the research community, but inviting the practitioner to publish with the researcher may conflate the research and practitioner systems and blur the roles of the actors. Thus far, we have argued that the interactive researcher is at risk of 'going native' if s/he involves him/herself in the goaloriented actions of the practice system. What if we turn things around? Would the reverse situation be less problematic than the researcher's participation in the goaloriented actions of the practice system?

In the case study, the implementation phase contained a situation in which the researcher role was tested. During this phase, the researcher collected data by observing the managers in their daily work. The researcher did not participate in the work itself but asked questions and discussed and observed events with the managers during calmer periods at work. During such an observation, one of the managers wanted the researcher to provide concrete guidance on how to become a better leader. The researcher was then obliged to refer to the 'contract' and explain that the purpose of this study was not to evaluate the managers and that the interactive researcher's role, in contrast with that of the consultant, was not designed to improve practice by offering such recommendations.

\section{Conclusion phase}

The last time that the interactive researcher switches roles is at the end of the research process. If the initial phase is devoted to supporting the project and the implementation phase is focused on stirring up and steering, the last phase may include any of these three roles, depending on the outcome of the research process. Here, the task for the researcher is to analyse data and publish results for the scientific community while returning the scientific results to the practice system for validation and discussion. A common method in interactive research is to arrange seminars in co-operation with the participating actors to create opportunities for joint analysis and a critical and reflective learning process (Argyris \& Schön, 1989; Svensson, Ellström \& Brulin, 2007). These seminars are an opportunity for respondents to validate data, to deepen the analysis and to gain further understanding of the material. The participants may react to the findings and contribute additional input and discussion (Larsson, 2006; Svensson \& Aagaard Nielsen, 2006). Seminars may employ different approaches depending on what the researcher chooses to focus on during the presentation. The first approach is a stirringup seminar where, for instance, issues of power are presented and critically discussed. 
Second, a seminar could be a supporting seminar, which focuses on enhancing understanding of a difficult issue for the practice system. Third, a steering seminar could be conducted that combines the presentation of research with guided discussions that follow a carefully planned agenda. The types of possible seminars are not limited to those discussed in this paper. We merely argue that stirring up, supporting and steering are important parts of the role of the interactive researcher. Seminars are likely to include all three aspects, although they may focus on one of them. The role of the interactive researcher as a virtual participant is important in this phase as well, but this role no longer consists primarily of taking a virtual stand on validity claims. The goal of the research may be to raise a truth claim that questions the practice (to which the research contributes by critiquing a model used in practice and suggesting alternatives) or to question a practical issue that the analysis indicated was normatively wrong (for example, how a company deals with gender issues or how it treats its employees in general). Finally, research can expose interviewees' expressive and subjective voices concerning the different aspects of practice.

Another significant dilemma is the risk of uncritically adopting the perspective of the practitioners. It is difficult to spend time in an organisation without being influenced by its language, local theories and culture. Thus, it is all the more important to keep scientific interest in focus and to balance the local and limited perspective with a holistic understanding, and it is important to attempt to see the value of practice without sacrificing theory generation and the search for generally applicable knowledge (Svensson, Ellström \& Brulin, 2007). It is necessary to remain grounded in the academic community and to continuously present and discuss the research project with other researchers. In this phase, it is important for the researcher's independence to be clearly identified. This means that the researcher must be allowed to be as critical as necessary and to appraise practical issues. One way of achieving this goal is to reach a consensus concerning the researcher's independence in the initial phase and include this in the mutual contract.

In the conclusion phase of the case study, three seminars were arranged in cooperation with the participating managers to create opportunities for joint analysis and a critical and reflective learning process. Based on the empirical data, a number of "mini-cases" that captured the actual work-related problems were constructed to serve as a point of departure for these discussions. In one of the seminars, the project manager role in the introduction of new products was specifically targeted. The observations of the work practices of managers had revealed a lack of communication among project 
managers, production managers, key account managers and planning managers. In the discussions, one manager accused the key account managers of occasionally 'top-down managing' projects, thereby circumventing the project manager. This accusation proved to be a point of contention with some of the other participants, and the discussion became a dispute. To move the discussion forward, the researcher intervened and posed a question regarding a basic assumption: why did they need a project manager? The managers reacted to the question with a surprised silence, and some of them subsequently began to laugh. As the discussion progressed, it was determined that this procedure had been an established company procedure that the managers now found difficult to justify. The need to coordinate the introduction of new products was indeed real, but the notion that this coordination had to be performed by a project manager could thus be questioned.

\section{Summary and concluding remarks}

In interactive research, we must ask how the interactive process is affected by the proximity between the research and practice systems. Thus, the following question was the main concern in this paper: how and to what extent should critical researchers engage in organisational action and processes of change? However, such a question raises further issues, and it seems appropriate to consider how to establish a mutually trusting relationship with practitioners without 'going native' and losing the researcher's critical edge. In this paper, we draw on Habermas' theory of communicative action to build an ideal typical project and thus a theoretical example of how to build mutual and trusting relationships in interactive research projects. However, these theoretical discussions were also infused with concrete examples that were drawn from a leadership case study that had employed an interactive research approach. Furthermore, and perhaps more importantly, we explore the concept of the virtual participant as a theoretical concept that can develop the understanding of what it means to be an interactive researcher.

We argue that in the initial phase, the focus should be on building a foundation for the joint learning cycles. It is necessary to create common goals and research questions that satisfy both the research and practice systems. This process is characterised as 'testing the water' by encouraging brainstorming activities and innovative thinking from all actors. Second, we argue for the need to establish mutual understanding concerning the means-end of the process. What are the goals of the process, and how should these 
goals be achieved? What are the different roles of the practice and the research systems? Third, we argue for the need to reach a consensus concerning the norms of action in the process. Time, openness and support are particularly important at the beginning of a project to allow the actors to reach a mutual understanding. In this phase, the interactive researcher, as a virtual participant, supports and steers the process while balancing this important role with his/her participation as an actor in the research system in the processes of reaching mutual understanding.

In the implementation phase, the main tension is the need to alternate between onstage performance and back-stage reflection (Eikeland, 2006). Here, the focus is on supporting and 'stirring up' the discussions by critically engaging the goal-oriented actions of the practice system without directly influencing it. Thus, during observations, interviews, focus groups and joint seminars, the researcher must take a virtual stand on truth claims, normative rightness and truthfulness without directly influencing the goaloriented actions in the practice system. This virtual involvement has three purposes: supporting, stir up and steer. Support is important when, for example, people violate prescribed norms. Stir up is important when discussions are limited by direct consensus without proper deliberation and steering is needed when individuals do not understand each other or fall into conflicts. Perhaps most importantly, the social scientific researcher's engagement as a virtual participant in the language process is necessary to achieve mutual understanding.

In the conclusion phase, the focus is primarily on presenting and discussing the research results with the practitioners. Three different forms of seminars have been outlined: the stirring-up seminar, the supporting seminar and the steering seminar. In this phase, the interactive researcher shifts from virtually raising validity claims to presenting her/his research results. These results may be related to raising or disproving truth claims in practice, questioning claims to normative rightness or, more importantly, providing room for interviewees' expressive and subjective statements concerning practical issues. Although we explain this issue in Habermasian terms, our purpose is primarily to discuss the role of the interactive researcher. Thus, we do not aim to promote the theory of communicative action as a mandatory perspective for analysis and interpretation. Interactive research should include a variety of epistemological and ontological perspectives to maintain a dynamic research platform. In this phase, it is important to specify the interactive researcher's independence. This means that the researcher must be allowed to be as critical as necessary and to appraise issues in practice. We argue that one way of achieving this aim is to reach consensus concerning 
the researcher's independence in the initial phase and to include this in the mutual contract.

We argue that the main benefit of this article is the novel concept of the virtual participant. This concept is helpful to explain how the interactive researcher can engage in performative action without becoming captive to the practice system. Another benefit is that the theory of communicative action presents the interactive researcher with a model that can be used to understand and create opportunities for actors to reach a mutual understanding. The initial phase addresses the idea of communicative rationality, and the implementation phase uses the idea of validity claims to inform discussions. This notion will create an opportunity for direct engagement in situations in which actions and communication occur to reach a deeper understanding.

This paper raised the following question: how and to what extent should critical researchers engage in organisational action and processes of change? We argue that the concept of a virtual participant can be useful when discussing the issues that are raised by this question. Five distinct implications for interactive researchers can be summarised based on the results of this paper. The interactive researcher as a virtual participant should perform the following actions:

1) Communicate with those whose meaning s/he seeks to understand

2) maintain distance from the goal-oriented actions of the practice system (division of labour),

3) participate by asking questions that are based on valid claims,

4) encourage participants to transcend pre-established consensus rules and correct misunderstandings in communication between participants in the project,

5) balance their position to ensure that it is neither neutral nor objective and not completely biased or subjective (in the subtle balance between these positions, the concept of the virtual appears to be plausible).

Based on these implications, we argue that the concept of virtual participant can enhance the quality of interactive and action research. The inclusion of the concept of virtual participant encourages researchers to engage in a critical reflection of the problems that are involved in taking different positions (i.e., subjective and close or objective and distant). It is important to note that these suggestions should not be viewed as a precise model; rather, they offer one way of interpreting the complex role of researchers participating in interactive and action research processes. 
It is necessary to address the limitations of the arguments in this paper. We have not explicitly addressed such issues as class, ethnicity and gender. There is also a need for focusing issues of power and instrumentalism more in-depth in relation to the concept of the virtual participant. Habermas' abstract description of the virtual participant is perhaps not perfectly compatible with real-world conditions. Thus, there are limitations to the applicability of our argument. Therefore, although this paper has informed the discussions of the role of interactive researchers, further explorations are needed. Future research should endeavour to more concretely study the notion of the virtual participant and further develop this concept for empirical use in interactive and action research projects and in relation to such issues as gender, power, ethnicity and class. We encourage such a future discussion.

\section{References}

Aagaard Nielsen, K., \& Steen Nielsen, B. (2006). Methodologies in Action Research. In K. Aagaard Nielsen, \& L. Svensson (Eds.), Action and Interactive Research. Beyond Practice and Theory (pp. 63-87). Maastricht: Shaker Publishing.

Amundsdotter, E. (2006). Interactive Research for Gender Equality in Workplaces. In K. Aagaard Nielsen, \& L. Svensson (Eds.), Action and Interactive Research. Beyond Practice and Theory (pp. 277-295). Maastricht: Shaker Publishing.

Argyris, C., \& Schön, D. (1989). Participatory Action Research and Action Science Compared. American Behavioral Scientist, 32(5), 612-623.

Bradbury et al. (2008). Action research at work: Creating the future following the path from Lewin. In The SAGE handbook of action research: participative inquiry and practice (pp. 77-92). London: Sage

Dick, B. (2004). Action research literature. Themes and trends. Action Research, 2(4), 425-444.

Dick, B. (2006). Action research literature 2004-2006. Themes and trends. Action Research, 4(4), 439-458.

Eikeland, O. (2006). Validity of Action Research and Validity in Action Research. In K. Aagaard Nielsen, \& L. Svensson (Eds.), Action and Interactive Research. Beyond Practice and Theory (pp. 193-240). Maastricht: Shaker Publishing.

Ellström, P.-E. (2008). Knowledge Creation Through Interactive Research: A Learning Approach. Paper presented at the ECER Conference, Gothenburg, September 10-12, 2008. 
Fournier, V., \& Grey, C. (2000). At the critical moment: conditions and prospects for critical management studies. Human Relations, 53(1), 7-32.

Greenwood, D. J., \& Levin, M. (1998). Introduction to action research. Social research for social change. London: Sage Publications.

Gunnarsson, E. (2006). The snake and the apple in the common paradise. In K. Aagaard Nielsen, \& L. Svensson (Eds.), Action and Interactive Research. Beyond Practice and Theory (pp. 117-142). Maastricht: Shaker Publishing.

Gunnarsson, E. (2007). Other Sides of the Coin. A Feminist Perspective on Robustness in Science and Knowledge Production. International Journal of Action Research, 3(3),349-363.

Gustavsen, B. (1992). Dialogue and development. Theory of communication, action research and the restructuring of working life. Assen: Van Gorcum.

Gustavsen, B. (1996). Action research, democratic dialogue, and the issue of 'critical mass' in change. Qualitative Inquiry, 2(1), 90-104.

Gustavsen, B. (1996). Vägen till bättre arbetsliv: strategier och arbetsformer i ett utvecklingsarbete. [The road towards better working life: strategies and forms of work in a developmental work project]. Stockholm: Arbetslivsinstitutet..

Gustavsen, B. (2008). Action research, practical challenges and the formation of theory. Action Research, 6(4), 421-437.

Habermas, J. (1984). The theory of communicative action, Volume 1. Reason and the rationalization of society. Cambridge: Polity Press.

Habermas, J. (1987). The theory of communicative action, Volume 2. Lifeworld and system: A critique of functionalist reason. Cambridge: Polity Press.

Habermas, J. (1995). Kommunikativt handlande. Texter om språk, rationalitet och samhälle. [Communicative action. Essays on language, rationality and society]. Göteborg: Daidalos.

Herr, K., \& Anderson, L. G. (2005). The action research dissertation. A guide for students and faculty. London: Sage Publications.

Holmquist, M. (2009). Interactive research and joint learning for practical contributions. Journal of Workplace Learning, 21(3), 240- 251.

Jacobs 2010

Johansson \& Lindhult 2008

Johnsen, H., \& Normann, R. (2004). When research and practice collide: The role of action research when there is a conflict of interest with stakeholders. Systemic Practice and Action Research, 17(3), 207-235. 
Johannisson, B., Gunnarsson, E. \& Stjernberg, T. (2008). Gemensamt kunskapande den interaktiva forskningens praktik. [Joint knowledge production - the practice of interactive research]. Acta Wexionensia Nr 149/2008. Växjö: Växjö University Press.

Kemmis, S. (2008). Critical theory and participatory action research. In Reason \& Bradbury (Eds.). The SAGE handbook of action research: participative inquiry and practice (pp. 121-138). London: Sage

Larsson, A.-C. (2006). Interactive Research. In K. Aagaard Nielsen, \& L. Svensson (Eds.), Action and Interactive Research. Beyond Practice and Theory (pp. 241-258). Maastricht: Shaker Publishing.

Lundin, R. A., \& Wirdenius, H. (1990). Interactive Research. Scandinavian Journal of Management, 6(2), 125-142.

Lykes \& Mallona

Morton, A. (1999). Ethics in action research. Systemic Practice and Action Research, 12(2), 219-222.

Maurer \& Githens

Newton, J. \& Goodman, H. (2009). Only to connect. System psychodynamics and communicative space. Action Research, 7(3), 291-312.

Nowotny, H., Scott, P., \& Gibbons, M. (2001). Re-thinking science. Knowledge and the public in an age of uncertainty. Cambridge: Polity Press.

Reason, P. \& Bradbury, H. (Eds.). (2008). The SAGE handbook of action research: participative inquiry and practice. London: Sage

Spicer, A., Alvesson, M., \& Kärreman, D. (2009). Critical performativity: The unfinished business of critical management studies. Human Relations, 62(4), 537560.

Svensson, L. (2002). Bakgrund och utgångspunkter. [Background and points of departure]. In L. Svensson, G. Brulin, P.-E. Ellström, \& Ö. Widegren (Eds.), Interaktiv forskning - för utveckling av teori och praktik (s. 1-22). [Interactive research - for development of theory and practice (pp. 1-22)]. Stockholm: Arbetslivsinstitutet.

Svensson, L., \& Aagaard Nielsen, K. (2006). A Framework for the Book. In K. Aagaard Nielsen, \& L. Svensson (Eds.), Action and Interactive Research. Beyond Practice and Theory (pp. 13-44). Maastricht: Shaker Publishing. 
Svensson, L., \& Brulin, G., \& Ellström, P.-E., \& Widegren, Ö. (Eds.). (2002). Interaktiv forskning - för utveckling av teori och praktik. [Interactive research - for development of theory and practice]. Arbetslivsinstitutet: Stockholm.

Svensson, L., Ellström, P.-E., \& Brulin, G. (2007). Introduction - on Interactive Research. International Journal of Action Research, 3(3), 233-249.

Svensson, L., \& Nilsson., B. (2008). Some practical and theoretical conclusions. In L. Svensson, \& B. Nilsson (Eds.), Partnership - As a strategy for social innovation and sustainable change (pp. 233-256). Stockholm: Santérus Academic Press.

Trondsen, M., \& Sandaunet, A.-G. (2009). The dual role of the action researcher. Evaluation and Program Planning, 32(1), 13-20.

Tydén, T. (Ed.). (2006). Aspects of Interactive Research in the Nordic Countries. In K. Aagaard Nielsen, \& L. Svensson (Eds.), Action and Interactive Research. Beyond Practice and Theory (pp. 143-192). Maastricht: Shaker Publishing.

Vehviläinen, M. (2006). Situated Agency in Interactive Research. In K. Aagaard Nielsen, \& L. Svensson (Eds.), Action and Interactive Research. Beyond Practice and Theory (pp. 317-331). Maastricht: Shaker Publishing.

Walker, B. \& Haslett, T. (2002). Action research in Management - Ethical dilemmas. Systemic Practice and Action Research, 15(6), 523-533.

Wallo, A. (2008). The Leader as a Facilitator of Learning at Work. A study of learning oriented leadership in two industrial firms. Linköping: Linköping Studies in Behavioural Science, No. 137.

Westlander, G. (2006). Researcher Roles in Action Research. In K. Aagaard Nielsen, \& L. Svensson (Eds.), Action and Interactive Research. Beyond Practice and Theory (pp. 45-62). Maastricht: Shaker Publishing.

Wicks, P. G., \& Reason, P. (2009). Initiating action research: Challenges and paradoxes of opening communicative space. Action Research, 7(3), 243-262. 